\title{
Rancang Bangun Sistem Informasi Aplikasi Sales Report Berbasis Web
}

\author{
Desy Apriani*, Rismawan Syaiful Anwar ${ }^{2}$, Robby Al Hamzah ${ }^{3}$ \\ ${ }^{1}$ Program Studi Sistem Informasi Universitas Raharja, ${ }^{2,3}$ Program Studi Teknik Informatika \\ Universitas Raharja \\ Email: *1desy@ raharja.info, ${ }^{2}$ rismawan@ raharja.info, ${ }^{3}$ robby.al@ raharja.info
}

\begin{abstract}
Abstrak
Perkembangan teknologi saat ini dinilai sangat berkembang dengan pesat, terutama dalam bidang industri. Persaingan dalam dunia industri semakin ketat sehingga perusahaan pun akan selalu berusaha agar terus menjadi yang pertama dalam memuaskan mitra perusahaan agar tidak beralih ke yang lain. Dalam melaksanakan pelaporan Sales Report masih menggunakan aplikasi berbasis office yakni Microsoft excel sehingga menyebabkan hasil kinerja yang tidak optimal. Maka dibangunlah sebuah sistem aplikasi Sales Report berbasis web. Dalam menentukan penelitian dan perancangan penelitian membutuhkan sebuah metode untuk melihat perkembangan dari perancangan dan penelitian tersebut, metode yang diterapkan antara lain menggunakan Metode SWOT (Strength, Weakness, Opportunities, Threat) dan dirancang menggunakan bahasas pemrograman PHP dan MySQL sebagai database.
\end{abstract}

Kata Kunci : Sistem, Sales Report, Laporan, Penjualan

\begin{abstract}
The development of technology is currently considered very rapidly developing, especially in the industrial field. Competition in the industrial world is getting tougher so that the company will always try to continue to be the first in satisfying the company's partners so they do not switch to another. In carrying out reporting, Sales Report still uses office-based applications, namely Microsoft Excel, which results in suboptimal performance results. Then a web-based Sales Report application system was built. In determining research and research design requires a method to see the development of the design and research, the methods applied include the SWOT method (Strength, Weakness, Opportunities, Threat) and are designed using $P H P$ and MySQL programming as a database.
\end{abstract}

Keywords : System, Sales Report, Reports, Sales

\section{Pendahuluan}

Perkembangan teknologi saat ini dinilai sangat berkembang dengan pesat. Setiap perusahaan baik swasta maupun pemerintahan sudah banyak yang merubah sistem dalam perusahaan masing-masing menjadi berbasis komputasi, yang dilakukan secara otomatis atau menggunakan komputer saja. Sistem pengolahan report saat ini dilakukan dengan cara semi komputerisasi dengan Microsoft Excel. Adanya kendala-kendala yang dihadapi ketika sistem pengolahan report menggunakan Microsoft Excel menyebabkan lambatnya kinerja dalam pembuatan laporan penjualan. oleh sebab itu, berdasarkan persoalan diatas mendorong penulis untuk membuat sebuah sistem sales report berbasis web dengan tujuan untuk membantu dan mempermudah pekerjaan dalam segi laporan penjualan. 


\section{TINJAUAN PUSTAKA}

\section{Sistem Informasi}

Sistem Informasi adalah sistem yang terdiri dari orang-orang dan computer yang memproses atau menafsirkan informasi.[1]

\section{Laporan Penjualan (Sales Report)}

Laporan Penjualan (Sales Report) adalah laporan yang berisi tentang transaksi penjualan baik itu per pelanggan maupun perinciannya. Dimana dasar dari laporan penjualan adalah Purchase Order (PO) yang dibuat oleh para penjual. Laporan penjualan juga memberikan peran yang sangat penting bagi perusahaan dalam menghitung cost rasio abtara biaya pengirirman disbanding dengan penjualan.[2]

\section{Web}

Www atau World Wide Web atau Web adalah sistem hypertext yang saling terkait dalam format dokumen yang berisikan berbagai informasi-informasi, baik berupa teks, gambar, suara, maupun video, dan informasi multimedia lainnya yang dapat diakses melalui perangkat yang disebut peramban web.[3]

\section{PHP}

PHP (Hypertext Preprocessor) adalah suatu bahasa pemrograman yang digunakan untuk menerjemahkan baris kode program menjadi kode mesin yang dapat dimengerti oleh computer yang bersifat server-side yang dapat ditambahkan ke dalam HTML.[4]

\section{MySQL}

MySQL adalah salah satu jenis database server yang sangat terkenal dan banyak digunakan untuk membangun aplikasi web dan database sebagai sumber pengelolaan datanya.[5]

Demikian pula yang didefinisikan penulis lain. MySQL adalah sebuah perangkat lunak sistem manajemen basis data SQL (database management system) atau DBMS yang multithread, multi-user, dengan sekitar 6 juta instansi diseluruh dunia.[6]

\section{Unified Modeling Language (UML)}

Unified Modeling Language (UML) adalah himpunan struktur dan teknik untuk pemodelan desain program berorientasi objek (OOP) serta aplikasinya. UML adalah metodologi untuk mengembangkan sistem OOP dan sekelompok perangkat tool untuk mendukung pengembangan sistem tersebut.[7]

\section{Literature Review}

Ada beberapa penelitian yang telah dilakukan dan memiliki korelasi yang searah mengenai sistem Sales Report. Dalam upaya menyempurnakan penelitian maka perlu dilakukan studi pustaka (Literature Review) sebagai salah satu dari penerapan metode penelitian yang dilakukan diantaranya yaitu:

1. Penelitian yang dilakukan oleh Adi Fajaryanto . 2017 dalam jurnal Ilmiah NERO Vol 3 No 2, dengan judul "Rancang Bangun Purwarupa Aplikasi Electronic Point Of Sales (EPOSAL) Berbasis Web Pada Mina Alumunium". Metode yang digunakan pada penelitian ini menggunakan metode Waterfall dengan menerapkan system EPOSAL yang dapat menyajikan informasi dengan baik.

2. Penelitian yang dilakukan oleh Sidik, Achmad dan Sutarman, Marlenih, 2017 dalam jurnal SISFOTEK GLOBAL ISSN : 2088 - 1762 Vol. 7 No. 1, dengan judul "Perancangan Sistem Informasi Penjualan Perumahan Citra Raya". Sistem ini digunakan untuk memudahkan dalam proses penjualan, promosi dan informasi detail tentang perumahan Citra Raya, metode perancangan dilakukan dengan menggunakan object oriented and 
design dan menggunakan Unified Modelling Language (UML). Sistem ini dugunakan untuk membantu mempermudah proses pendataan serta dapat memenuhi kebutuhan informasi yang selama ini sulit untuk dipenuhi.

3. Penelitian yang dilakukan oleh Muhammad Nasihin. 2019 dalam Jurnal Teknologi \& manajemen informatika Vol.5 No.2, dengan judul "Rancang Bangun Sistem Informasi Point of Sales (POS) Pada CV. Arema Alam Abadi”. Sistem ini digunakan untuk memudahkan dalam proses kerja dan meningkatkan keakuratan dalam pengolahan data penjualan dan pelaporan yang berlangsung. Metode pengembangan perangkat lunak yang digunakan adalah metode prototype untuk menggali spesifikasi kebutuhan pelanggan secara lebih detil.

4. Penelitian yang dilakukan oleh Catur Cahyodi, Saputro dan Rita Wahyuni Arifin. 2017 dalam jurnal Jurnal Information System for Educators and Professionals (ISBI), dengan judul "Sistem Informasi Point Of Sales Berbasis Web Pada Colony Amaranta Bekasi". Sistem ini dirancang dan dibangun untuk mencatat transaksi penjualan dan mengolah data pada klinik dan spa Colony Amaranta untuk membantu jalannya kegiatan operasional dan mempercepat proses pelayanan mulai dari proses pendaftaran sampai pembayaran. Metode yang digunakan adalah metode Waterfall menggunakan Linear Sequential Model.

\section{Metode Penelitian}

Metode yang digunakan pada penelitian ini menggunakan metode analisis SWOT, dimana metode ini digunakan untuk mengidentifikasi kekuatan (Strenght), kelemahan (Weakness), peluang (Opportunities), dan ancaman (Threat) dari sebuah komponen penelitian. Analisis SWOT adalah analisis masalah terhadap kegiatan penting yang sama pentingnya dengan proses pengambilan keputusan. [8]

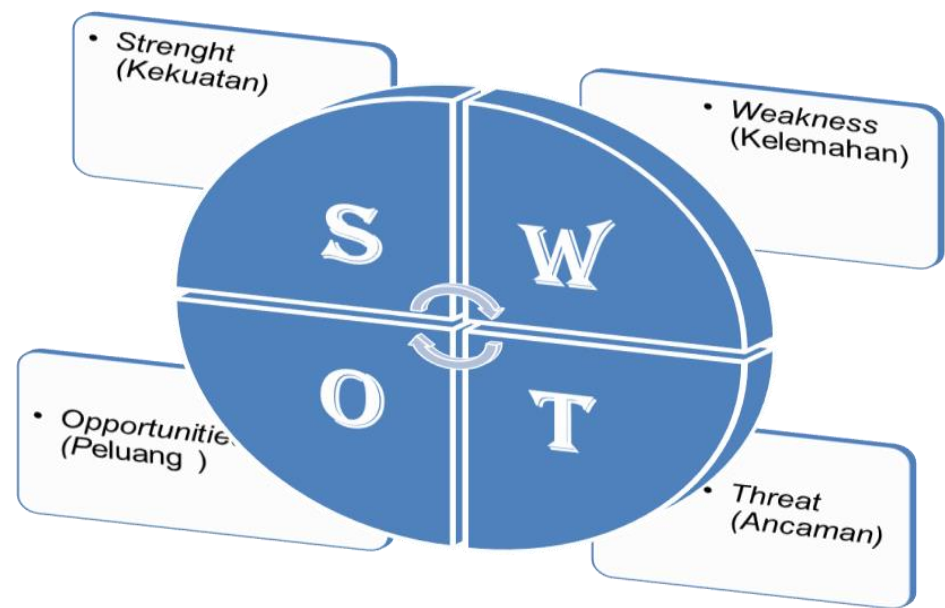

Gambar 2.1 Metode Analisi SWOT

3. Hasil dan Pembahasan

Untuk dapat menggambarkan aliran informasi dan transformasi yang diaplikasikan pada saat data bergerak dari input menjadi output dibutuhkan beberapa tahapan analisa dalam merancang model diagram database dan model rancangan sistem diantaranya : 


\section{UseCase Diagram Diusulkan}

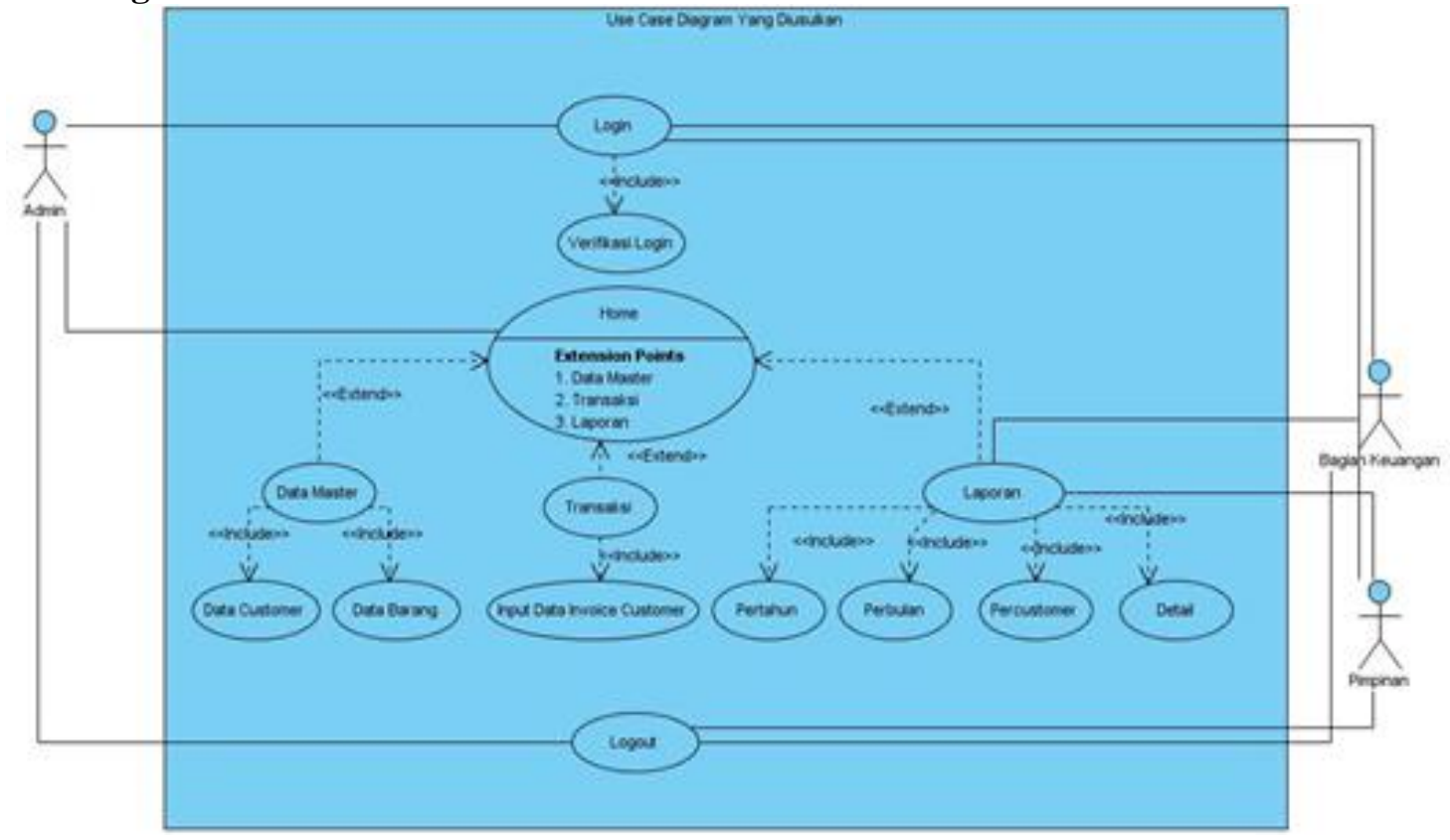

Gambar 3.1 Use Case diagram Diusulkan

Pada gambar diatas terlihat bahwa admin melakukan login terlebih dahulu, setelah berhasil login admin masuk kedalam menu input data customer dan data barang kemudian admin menginput data transaksi penjualan sehingga menjadi sebuah laporan penjualan yang dapat dilihat oleh Pimpinan dan Bagian Keuangan

\section{Activity Diagram Diusulkan}

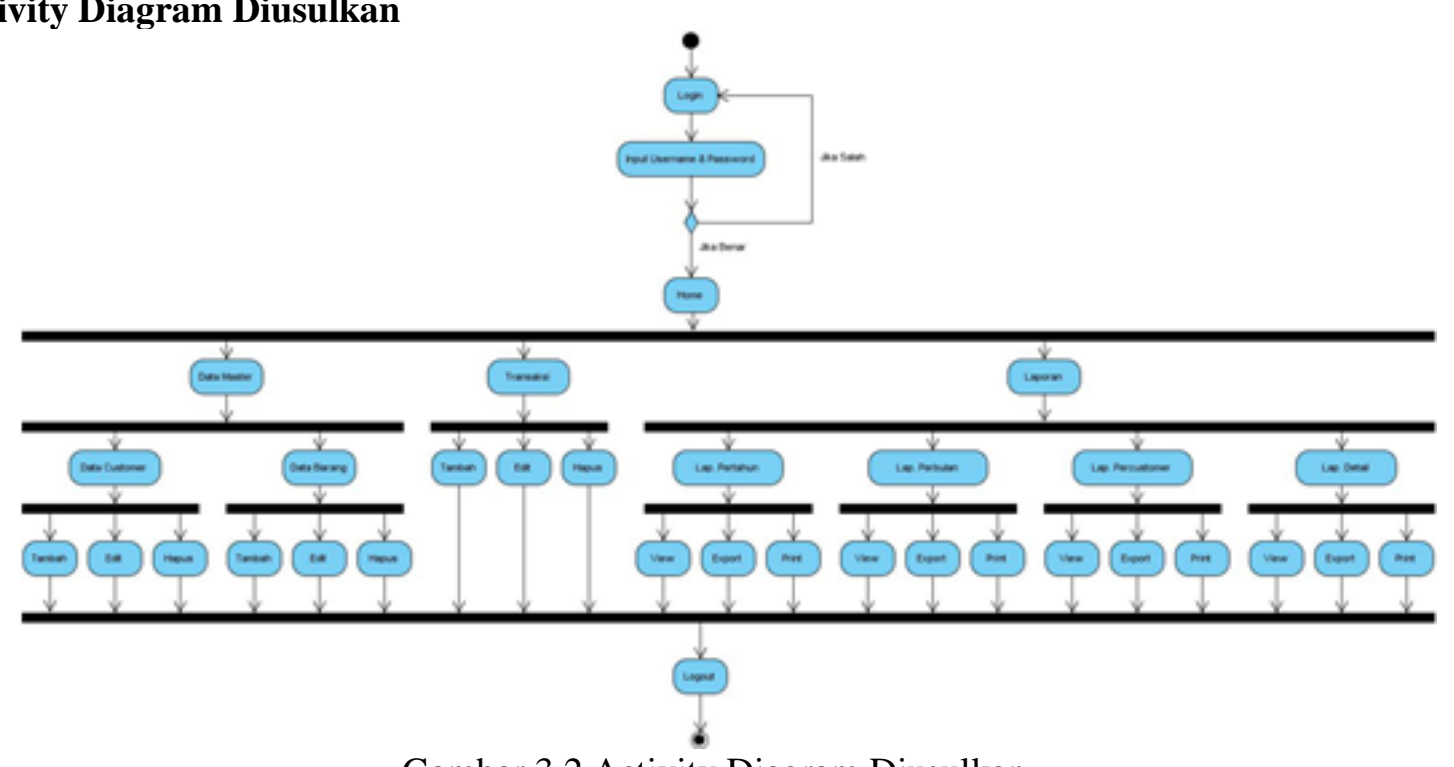

Gambar 3.2 Activity Diagram Diusulkan

Pada gambar diatas terlihat bahwa Admin harus melakukan login terlebih dahulu dengan memasukkan username dan password yang benar dengan hak akses dapat menginput data customer dan data barang kemudian admin menginput data transaksi penjualan sehingga menjadi sebuah laporan penjualan yang dapat dilihat oleh Pimpinan dan Bagian Keuangan. 


\section{Sequence Diagram Diusulkan}

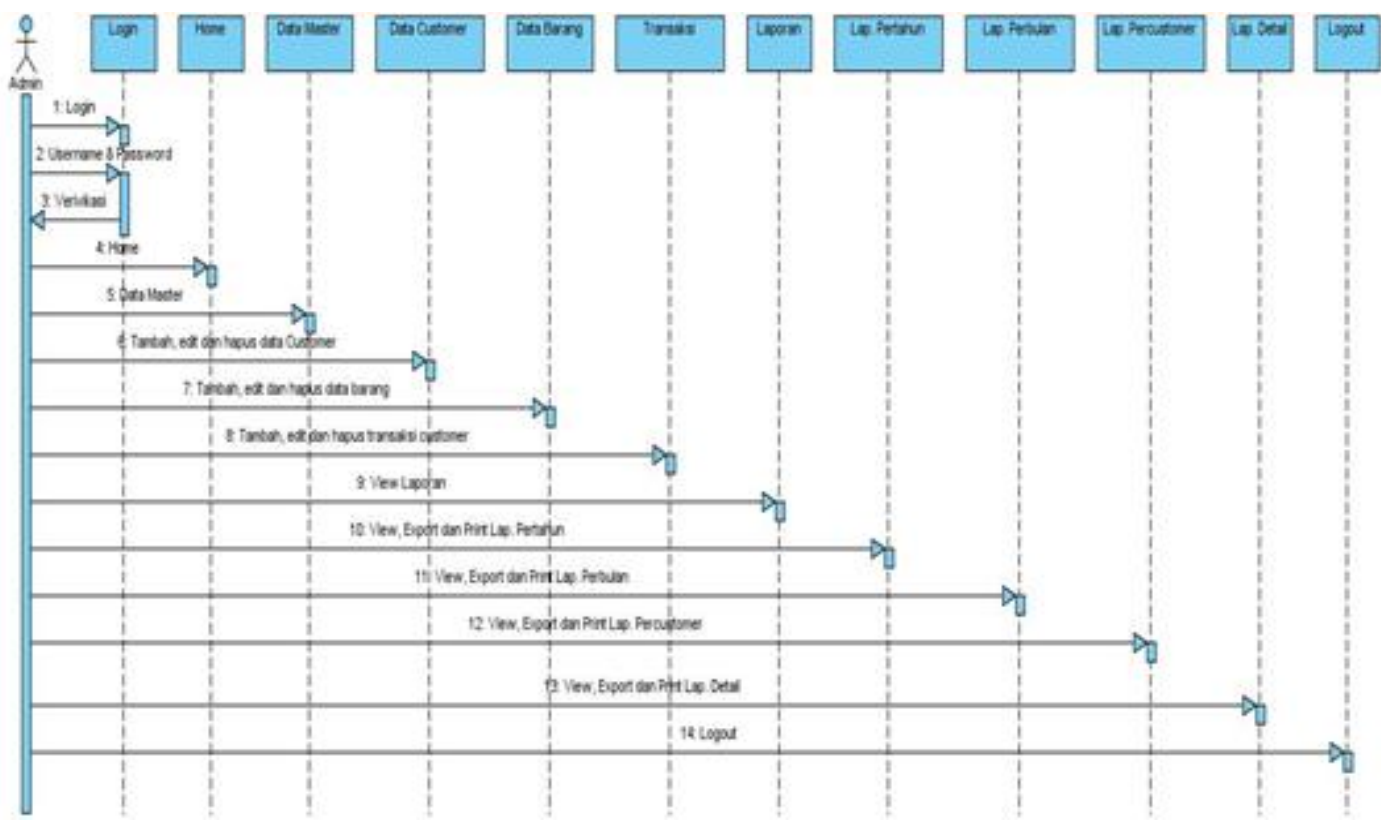

Gambar 3.3 Squence Diagram Diusulkan

Pada gambar diatas terdapat, satu aktor yaitu admin dapat melakukan login terlebih dahulu dengan memasukkan username dan password yang benar, setelah berhasil login, admin dapat menggunakan menu data master, data customer, data barang, data transaksi, dan data laporan, setelah selesai admin dapat logout dari sistem.

\section{Desain Rancangan Program}

langkah selanjutnya yaitu hasil dari implementasi yang merupakan langkah dalam menentukan apakah aplikasi yang dirancang sesuai dengan tujuan akhir atau tidak.

a. Tampilan Menu Data Barang

\begin{tabular}{|c|c|c|c|c|}
\hline ane & 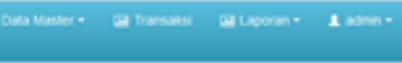 & & $\begin{array}{l}\text { Sisten } \\
\text { nawa }\end{array}$ & port PT TSA \\
\hline$-m$ & 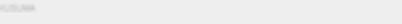 & & & \\
\hline Nis & & & & $+\|=$ \\
\hline & & & & \\
\hline$\Rightarrow$ & 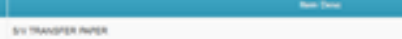 & $=$ & metasen & \\
\hline$\therefore=$ & and & $=$ & moseans & \\
\hline , & $=-\infty+\infty$ & $=$ & mosemson & \\
\hline . $\infty$ & $n=\infty .0000$ & $\infty$ & moseneso & \\
\hline , = & 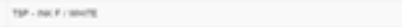 & $=$ & mostans & \\
\hline$\therefore=$ & nanticesen & $=$ & moseme- & \\
\hline$n$ & w.metime & $=$ & monnesin & \\
\hline . $=$ & 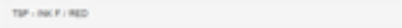 & $=$ & mosenas & \\
\hline$\infty$ & 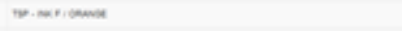 & $=$ & movemanes & \\
\hline$==$ & nimisent & $=$ & mosemans & \\
\hline$\cdots$ & nising & $=$ & mosenses & \\
\hline$\theta=$ & nexprinear & $=$ & mosemano & \\
\hline$\cdots$ & n.mon & $\Rightarrow$ & mowas-s & \\
\hline$\approx x$ & 1 & $=$ & mosesens & \\
\hline 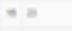 & 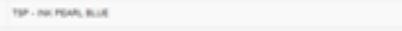 & $=$ & mosemans & \\
\hline
\end{tabular}

Gambar 3.4 Tampilan Menu Data Barang

Pada Gambar diatas menjelaskan data-data barang yang digunakan untuk mengelola data barang yang dilakukan oleh bagian Admin. Menu data barang bisa dilakukan dengan beberapa fungsi antara lain menu edit, menu tambah dan menu hapus. 
b. Tampilan Menu Input Transaksi

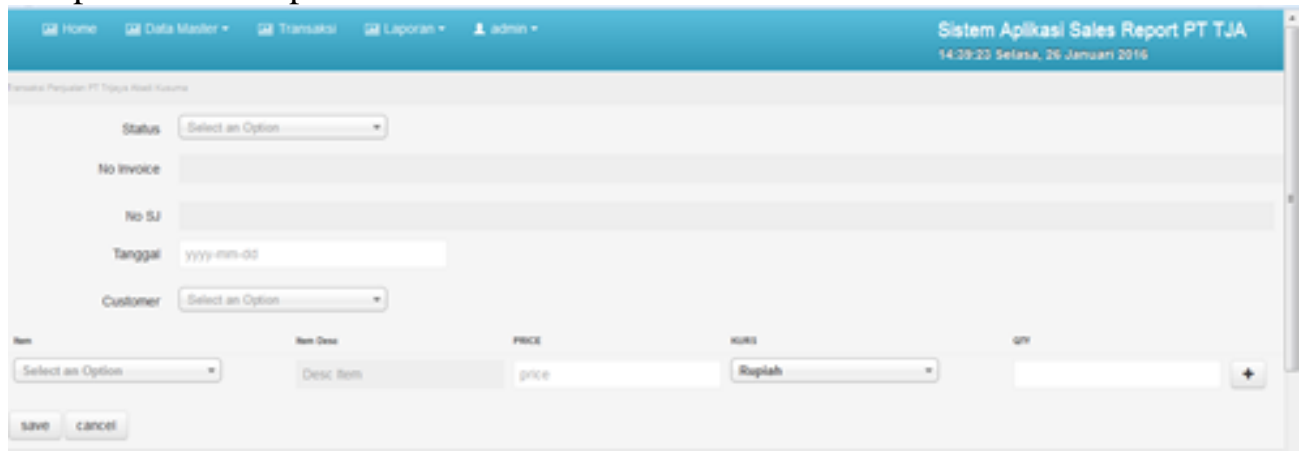

Gambar 3.5 Tampilan Menu Input Transaksi

Pada Gambar diatas menjelaskan transaksi yang digunakan untuk memasukkan data penjualan barang dan terdapat beberapa fungsi yaitu menu simpan dan menu cancel.

c. Tampilan Menu Laporan

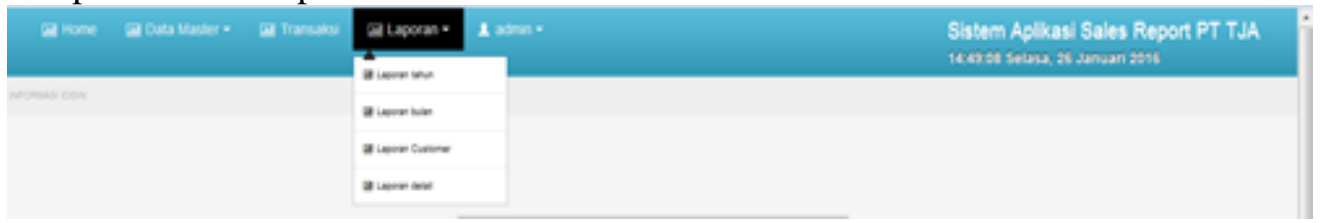

Gambar 3.6 Tampilan Menu Laporan

Pada Gambar diatas menjelaskan data laporan yang dihunakan untuk melaporkan semua data baik data penerimaan, penjualan dan retur. Pada menu laporan terdapat 4 menu yaitu laporan perhari, laporan perbulan, laporan pertahun, dan laporan customer.

\section{Kesimpulan}

Dengan adanya sistem yang dibuat diharapkan dapat membantu dan mempermudah kinerja dalam melakukan pembuatan dan perekapan laporan menjadi lebih cepat, tepat dan menghasilkan hasil yang akurat.

\section{Daftar Pustaka}

[1] Mulyani, Sri., dkk. 2018. Sistem Informasi Akuntansi : Aplikasi Disektor Publik. Bandung: Unpad Press

[2] M. Royan, Frans. 2011. Menjadi Penjualan Profesional Ala Sun Tzu. Yogyakarta: Kanisius (Anggota IKAPI)

[3] Santoso, Herry., Nur Fauziah. 2019. Pencitraan Visual Kawasan Urban : Teknik Pengembangan Sistem Multimedia Spasial 3D. Malang : UB Press

[4] Supono., Virdiandry Putratama. 2018. Pemrograman Web Dengan Menggunakan PHP dan Framework Codeigntier. Yogyakarta: Deepublish (Group Penerbitan CV Budi Utama)

[5] Harianto, Kusno., Heny Pratiwi dan Yonatan Suhariyadi. 2019. Sistem Monitoring Lulusan Perguruan Tinggi Dalam Memasuki Dunia Kerja Menggunakan Tracer Study. Surabaya: Media Sahabat Cendekia 
[6] Haqi, Bay., Heri Satria Setiawan. 2019. Aplikasi Absensi Dosen dengan Java dan Smartphone sebagai Barcode Reader. Jakarta: PT Elex Media Komputindo

[7] Bunyamin, Sulpadianti., dan Cahyo Prianto. 2020. Pembuatan Aplikasi Clustering Gangguang Jaringan Menggunakan Metode K-Means Clustering. Bandung: Kreatif Industri Nusantara

[8] Utaminingsih, Alifiulahtin., Ita Rifiani Permatasari., dan Mohammad Maskan. 2018. Kewirausahaan. Malang: Polinema Press 